\title{
Comparative Study Between Leishman's Stain and Giemsa Stain on Routine Peripheral Smear Examination
}

\author{
Dhakshinya. $\mathrm{M}^{1}$ and M. P. Brundha ${ }^{1 *}$ \\ ${ }^{1}$ Department of Pathology, Saveetha Dental College and Hospitals Saveetha Institute \\ of Medical and Technical Sciences Saveetha University, Chennai- 600077, India \\ ${ }^{1 *}$ Associate Professor, Department of Pathology, Saveetha Dental College and Hospitals, Saveetha \\ Institute of Medical and Technical Sciences, Saveetha University, Chennai-77, Tamilnadu, India
}

\section{ABSTRACT}

Leishman stain, a type of Romanowsky stain, is a mixture of Methylene blue and Eosin dye. It is prepared in alcohol and is diluted using distilled water. It stains human cells purple in colour. It is one of the best methods preferred for peripheral blood smear examination. Giemsa stain has been named after a German chemist and bacteriologist Gustav Giemsa and used in histopathological diagnosis of malaria and various other parasites. Comparative study in between Leishman's stain and Giemsa stain was done. Randomly selected 20 peripheral blood samples were used for this study. Two Peripheral smears were prepared from each sample with a total of forty smears. The first group of twenty smears was selected from each sample and stained with routine Leishman's stain and the second group of twenty smears from each sample was stained with Giemsa stain. The morphology of the blood cells was analysed by a pathologist in an unbiased manner. The scores were analysed statistically. The smears were kept for storage after mounting with DPX mounting media. This study shows that Giemsa staining is a better alternative for Leishman's staining for a routine peripheral smear examination and this also has advantages of finding other abnormalities in blood such as other blood element abnormalities. Due to no significant difference seen in staining property in between Leishman's stain and Giemsa stain, we can very well use Giemsa stain as an alternative to Leishman stain.

KEY WORDS: GIEMSA STAIN; LEISHMAN STAIN; PERIPHERAL SMEAR; HISTOPATHOLOGY; PARASITES; INFECTION.

\section{INTRODUCTION}

Human blood is made up of both liquid and solid components in which the liquid part is called plasma, is made up of water, salt and protein (Fridman, 2008). The most important part to know is that the solid part of our blood contains red blood cells, white blood cells

\section{ARTICLE INFORMATION}

${ }^{*}$ Corresponding Author: brundha.sdc@saveetha.com Received 10th June 2020 Accepted after revision 4th August 2020 Print ISSN: 0974-6455 Online ISSN: 2321-4007 CODEN: BBRCBA

Thomson Reuters ISI Web of Science Clarivate Analytics USA and Crossref Indexed Journal

\section{Clarivate}

NAAS Journal Score 2020 (4.31) SJIF: 2020 (7.728)

A Society of Science and Nature Publication,

Bhopal India 2020. All rights reserved.

Online Contents Available at: http//www.bbrc.in/

Doi: http://dx.doi.org/10.21786/bbrc/13.7/43 and platelets. Any abnormalities in blood are easily diagnosed by a blood film which is also known as peripheral blood smear which is defined as a thin layer of blood smeared on a glass slide and then stained in such a way that blood cells can be examined properly under microscope (Mohan, 2013). This peripheral smear gives us information about the number and shape of the cells in blood which will help the doctors in early diagnosis of blood disorders('Peripheral smear discloses histoplasmosis', 2010).

A complete blood smear examination begins with a visible scrutiny for acceptable quality of smear, stain and absence of macroscopic starches (Maslak, 2004). An 
appropriate smear is then examined under the microscope in $10 \mathrm{X}$ magnification, to recheck the stain quality and to make sure the smear is free of Clumps of platelets, white blood cells or red blood cells, any sort of living micro-organism, Rouleaux formation, Microfilaments and Protein strands(Renu and Pati, 2008).

Leishman stain, a type of Romanowsky stain, is a mixture of Methylene blue and Eosin dye (Bohatirchuk, 1957). It is prepared in alcohol and is diluted using distilled water. It stains human cells purple in colour. It is one of the best methods preferred for peripheral blood smear examination. The Leishman stain was first discovered by a British surgeon W. B (Korson, 1951). Leishman. It consists of an acidic stain eosin and a basic stain methylene blue. It is capable of fixing the smear to the slide there by prefixing steps can be avoided. The various methods in which Leishman's stain is used are, a) Differential Leucocyte Count, b) Determination of Type of Anemia, c) Platelet count. The stain must be diluted with a phosphate buffer in order to achieve very accurate results(Aspinall, 2014). The ideal pH would be 6.8 for morphological studies of blood cells, while a $\mathrm{pH}$ of 7.2 is required for parasitic studies (Villanueva, 1974).

Morphology of a normal red blood corpuscle is a biconcave disc shaped with a diameter measuring about 7-8um, with a central pallor (Cox and Cunliffe, 1979). To perform it function to the fullest a mature red blood cell lacks a nucleus. Red blood cells are stained in pink with Romanowsky stain as the haemoglobin picks up eosin stain(Bessman, 1978). Development in the marrow, cells that belong to leukocytes of the granulocytic series, neutrophils, eosinophils, and basophils, synthesize proteins and store them as cytoplasmic granules. When specific granules start appearing that marks the progression of the promyelocyte to neutrophilic, eosinophilic, or basophilic myelocytes (Culp-Hill et al., 2018). Thereafter, the cell continues maturation into an amitotic cell with a segmented nucleus, capable of ameboid motility, phagocytosis, and microbial killing (Mathur, 2006). The mature granulocytes also develop cytoplasmic and surface structures that permit them to attach to and penetrate the wall of venules(Strange and Marnell, 1985; Mathur, 2006). The mature granulocytes enter the blood from the marrow, circulate briefly, and move to the tissues to carry out their major function of host defense(Sivakumaran, 2001).

Giemsa stain has been named after a German chemist and bacteriologist Gustav Giemsa and used in histopathological diagnosis of malaria and various other parasites (Ramalingam et al., 2018). This is also a differential stain, for example when Giemsa stain is combined with Wright stain it gives Wright-Giemsa stain (Mehlhorn, 2016). This stain is a classic blood film stain for peripheral blood smears and also in bone marrow specimens. Giemsa stain contains a mixture of Azure, Methylene blue and Eosin dye (Lisanti and Stockert, 1974). Methylene blue is a basic dye which stains the acidic component in the smear and Methanol acts as a fixative and also for cellular staining (Frink, 1965). This is available in two forms one is stock solution and the other one is working solution. Working solution has to be done by the laboratory person where if we add 30 drops of stock solution of Giemsa stain to $30 \mathrm{ml}$ of distilled water respectively (Frink, 1965; Tyler, 1980).

\section{MATERIAL AND METHODS}

Peripheral Blood Collection: Peripheral Blood samples were collected from randomly 20 patients who were taking their routine blood examination at the Clinical Laboratory in Saveetha Dental Hospital in Chennai, after obtaining the consent from the respective individuals. Approval was given by the ethical committee for working on research involving humans in Saveetha Institute of Medical and Technical Sciences (SIMATS). The criterion for selecting the sample was the clinical request for Haemoglobin and Complete blood count. No restriction was made for age, sex, or clinical history of each patient under clinic care. All the procedures were carried out in the clinical laboratory of Saveetha Dental College, Saveetha Institute of Medical and Technical Sciences in the month of November 2019.

Peripheral Blood Smear Preparation: Forty slides were taken to prepare a set of two slides of smear for each blood sample to compare the different staining. The slides were labelled with a glass pencil by the name of the patient from whom the blood was taken. Just near the label a small drop of blood was placed for the smear preparation (Marwaha, 2010). A separate clean slide was taken and held at $45^{\circ}$ angle from the slide containing the blood drop about $1 \mathrm{~mm}$ above the blood drop. The slider was pulled back over the blood drop and waited until the blood spread over the full edge of the slide. After this the slide was pushed forward until the other end of the slide in order to achieve an evenly spread tongue shaped smear. Any excess blood on the sides was wiped off with clean tissue paper. One labelled slide was placed inside a coplin jar of Methanol, while the other was left to air dry (Mohan, 2017).

\section{Staining:}

Leishman's Staining: The air-dried labelled slide is taken and placed on the staining rack with the right side facing up. Commercially available Leishman's stain was filtered and taken in a dispensing bottle. Few drops of Leishman's stain were poured on the slide to cover the blood smear from the head to the tail end of the slide and left for 2 minutes. After 2 minutes, double the amount of distilled water was poured on the slide to cover the whole smear, and left for 10 minutes. After 10 minutes, the slide was taken and washed under running tap water by holding the palm over the head end and directing the water on the slide concerning to not lose the contents of the slide with the flow of the water. The slide is later air-dried. A drop of Cedar Wood Oil was placed on the slide and viewed under a microscope (Mohan, 2017). 
Giemsa Staining: Working solution has to be prepared after preparing the smear in a coplin jar which contains methanol we will have to keep the glass slide for 3-5 minutes after this we will have to immediately keep inside the coupling jar of the working solution we prepared for 30 minutes after this we will have to wash the slide carefully and air dry it. Later a drop of Cedar wood oil was placed on the slide mainly in the tail region so that RBC's will be scattered all over and examined under the microscope (Emsweller and Stuart, 1944; Mohan, 2017).

Figure 1: A representative photomicrograph of Leishman stained smear of this study

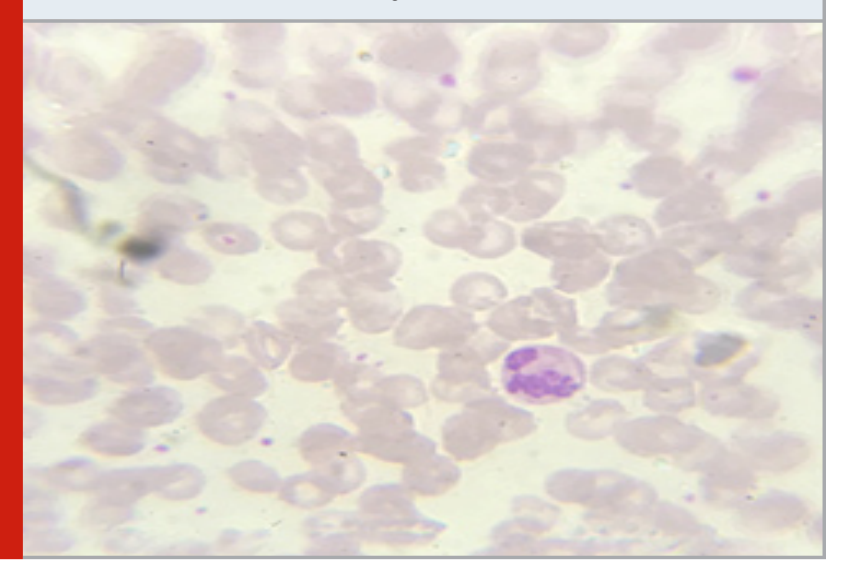

Figure 2: A representative photomicrograph of Giemsa stained smear of this study.

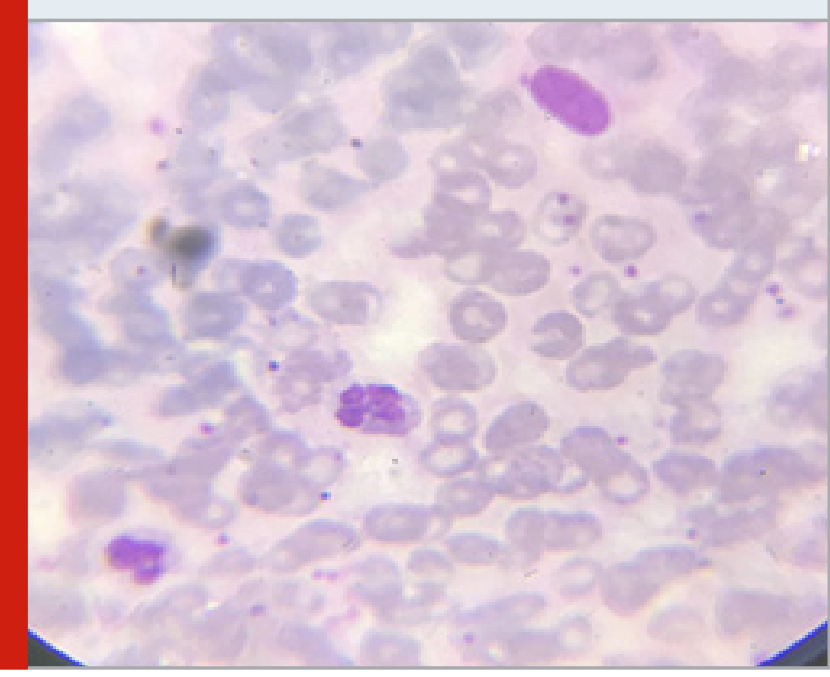

\section{RESULTS AND DISCUSSION}

The labelled slides were carefully analyzed under a microscope under various categories such as: Staining Technique, Morphology of RBCs, WBCs and Platelets. The analyzed slides were graded accordingly. In our study we used the Likert bipolar-scale grading method where 0 is not acceptable and 1 means acceptable [Table 1].

As the Table 2 and 3 and the figure 1 and 2, WBC's Nuclear detail were acceptable, the percentage in
Leishman's stain was 96\% and in Giemsa was 95\%, There was no significant difference in the WBC's nuclear detail when compared in our study. But the unacceptable percentage was 4\% and 5\% respectively. WBC's cytoplasmic acceptance percentage was 99\% for Leishman's and 94\% for Giemsa.Here also there was no significant difference and unacceptable percentage was $1 \%$ and $6 \%$ respectively. Platelet staining was $98 \%$ in both Leishman and Giemsa stain but the unacceptable percentage was very low and it is $2 \%$. RBC's staining acceptable percentage was $98 \%$ in both Leishman and Giemsa staining. The background staining which obtained from both the staining was the same, as the acceptable percentage for Absence of background staining which was 90\% in both Leishman and Giemsa staining and unacceptable percentage was 10\% which can be avoided by proper cleaning procedures. The statistical analysis of the grades (results), were done and shown in Table 4.

Table 1. Likert bipolar scale of the acceptability, where 0 is not acceptable and 1 is acceptable.

\begin{tabular}{|l|c|}
\hline GRADES & \\
\hline 0 & Not Acceptable \\
\hline 1 & Acceptable \\
\hline
\end{tabular}

Table 2. The results of Leishman's stain.

\begin{tabular}{|l|c|c|}
\hline FEATURES & $\begin{array}{c}\text { TOTAL } \\
\text { ACCEPTABLE } \\
\text { SCORES (\%) }\end{array}$ & $\begin{array}{c}\text { TOTAL } \\
\text { UNACEPTABLE } \\
\text { SCORE (\%) }\end{array}$ \\
\hline WBC's Nuclear detail & 96 & 4 \\
\hline $\begin{array}{l}\text { WBC's cytoplasmic } \\
\text { details }\end{array}$ & 99 & 1 \\
\hline platelets staining & 98 & 2 \\
\hline RBC's & 98 & 2 \\
\hline $\begin{array}{l}\text { Absence of background } \\
\text { staining }\end{array}$ & 90 & 10 \\
\hline
\end{tabular}

Table 3. The results of Giemsa Stain

\begin{tabular}{|l|c|c|}
\hline FEATURES & $\begin{array}{c}\text { TOTAL } \\
\text { ACCEPTABLE } \\
\text { SCORES (\%) }\end{array}$ & $\begin{array}{c}\text { TOTAL } \\
\text { UNACCEPTABLE } \\
\text { SCORE (\%) }\end{array}$ \\
\hline WBC's Nuclear detail & 95 & 5 \\
\hline WBC's cytoplasmic & 94 & 6 \\
details platelets staining & 98 & 2 \\
\hline RBC's & 98 & 2 \\
\hline $\begin{array}{l}\text { Absence of background } \\
\text { staining }\end{array}$ & 90 & 10 \\
\hline
\end{tabular}

In this study we used Mann Whitney Ranksum analysis. The one tailed P-value obtained was 0.600 , which was $>0.05$. Hence, there is no significant difference 
between the two staining methods. Both Leishman and Giemsa stains were comparatively the same and there was no significant difference in Morphology of RBCs, WBCs and platelets (Ramalingam et al., 2018).

Table 4: Statistical results of Leishman and Giemsa stain.

\begin{tabular}{|l|c|c|}
\hline $\begin{array}{l}\text { GROUP } \\
\text { NAME }\end{array}$ & MEAN & $\begin{array}{l}\text { STANDARD } \\
\text { DEVIATION }\end{array}$ \\
\hline Leishman's stain & 96.2 & 3.633 \\
\hline Giemsa stain & 95 & 3.137 \\
\hline Difference & 1.2 & \\
\hline
\end{tabular}

The background staining may be avoidable in both Giemsa and Leishman's stain. This study shows that Giemsa staining is an better alternative for Leishman's staining for routine blood smear and Leishman stain can be a better alternative for quantification of malarial parasites in case of unavailability of Giemsa stain and this also has advantages of finding other abnormalities in blood such as other blood elements abnormalities. Parasite count was compared between these two staining methods and they were highly correlated with each other and these methods showed a high level of agreement (Padma et al., 2018). As the study by Bower et al the effect of the Leishman's stain on the peripheral smear for the purpose of analysis was better and showed clearer results compared to the staining of Giemsa stain. The cells were more evident and recognizable in Leishman's stain. The Giemsa stain had also stained enough to make the cells visible while the proper anatomy was not appreciated(Isaiah et al., 2018).

The morphology of RBCs was maintained properly in the slide stained with Leishman's stain. Disc shaped round cells with centre pallor were appreciated. They were easily differentiable from other cells in the blood (Cunningham, 1969). On the other hand, the RBCs in the slides stained with Giemsa stain had mostly lysed and lost their morphological structure. The morphology of WBCs was maintained properly in the slide stained with Leishman's satin. The different types of leukocytes were effortlessly found out. There weren't any discrepancies that affected the analysis of the smear. The WBCs in the slide that was stained with Giemsa stain were appreciable. The different leukocytes were able to be located based on the shape and the number of lobes in the nucleus (Cunningham, 1969; Raju, 1982). Leishman-stained slides compared to Giemsa. Red cells stained with Giemsa result in a more bluish tinge than with Leishman stain (Sareen, Kapil and Gupta, 2018). This makes the contrast of the parasitic cytoplasm with Giemsa less appreciable.

In the thick smear preparation Giemsa stain was subjectively superior to Leishman. However, this did not translate into reduced sensitivity or reduced accuracy in quantitation in the series: only one case was missed with Leishman stain, and in general thick smear reading was not more difficult in preparations stained with Leishman
(Mathur, Tripathi and Kuse, 2013). In Leishman-stained slides, detection of these late-stage parasites was easier compared with Giemsa. Red cells stained with Giemsa have a more bluish tinge than Leishman stain does (Baird, 1936). The difference between stain on Leishman and stain on Giemsa found in our study is that the Leishman method of staining provides better representation of the cells ' nuclear chromatin patterns (Ramalingam et al., 2018).

Giemsa staining is most widely used to stain chromosomes directly in the DNA region in order to detect rearrangement and translocations (Baird, 1936; Meyer, 1945). Giemsa stain was subjectively superior to Leishman stain in the dense smear preparation. Red cells stained with Giemsa stain have a more bluish tinge than Leishman stain does (Leishman, 1901). For morphological evaluation of leukocytes Leishman stain was superior to Giemsa stain. Compared with Giemsa stain, the finer chromatin pattern and nucleus color was clearer with Leishman stain (Doddagowda, 2017). Limitations of this study were less sample size, availability of the pathologist for the scoring of the smears. Future studies may be done with increased sample size and inclusion of three to four expert pathologists for analysing the smears.

\section{CONCLUSION}

Within the limitations of the study we conclude that due to no significant difference seen in staining property in between Leishman's stain and Giemsa stain, we can very well use Giemsa stain as an alternative to Leishman stain in case of unavailability of stains and poor-quality stain lots.

\section{ACKNOWLEDGEMENTS}

We thank Saveetha Dental College and the participants of this study for their support to conduct the original study.

Conflict of Interest: None to declare

\section{REFERENCES}

Aspinall, V. (2014) Clinical Procedures in Veterinary Nursing. Elsevier Health Sciences.

Baird, T. T. (1936) 'Comparative Study of Dehydration', Stain Technology, pp. 13-22. doi: 10.3109/10520293609111317.

Bessman, D. (1978) 'Microcytosis Caused by RBC Fragmentation', JAMA. doi: 10.1001/ jama.1978.03280500071027.

Bohatirchuk, F. P. (1957) 'Stain Historadiography', Stain Technology, pp. 67-74. doi: 10.3109/10520295709111404.

Cox, K. O. and Cunliffe, D. A. (1979) 'Densitydependent fractionation of murine RBC: Antigenic relationships between young RBC and old RBC and bromelain-treated RBC', Clinical Immunology and Immunopathology, pp. 394-401. doi: 10.1016/0090- 
1229(79)90080-1.

Culp-Hill, R. et al. (2018) 'Effects of red blood cell (RBC) transfusion on sickle cell disease recipient plasma and RBC metabolism', Transfusion, pp. 2797-2806. doi: 10.1111/trf.14931.

Cunningham, J. L. (1969) 'Rapid Alkaline Rehydration of Dried Plant Tissues for Histologic Study', Stain Technology, pp. 243-246. doi: 10.3109/10520296909063359.

Doddagowda, S. M. (2017) 'Leishman-Giemsa Cocktail Is it an Effective Stain for Air Dried Cytology Smears', JOURNAL OF CLINICAL AND DIAGNOSTIC RESEARCH. doi: $10.7860 / j \mathrm{jdr} / 2017 / 25553.9490$.

Emsweller, S. L. and Stuart, N. W. (1944) 'Improving Smear Technics by the Use of Enzymes', Stain Technology, pp. 109-114. doi: 10.3109/10520294409105839.

Fridman, A. (2008) Plasma Chemistry. Cambridge University Press.

Frink, R. S. (1965) 'Staining Cells on a Membrane Filter with Giemsa Stock and Tap Water', Stain Technology, pp. 367-369. doi: 10.3109/10520296509116446.

Isaiah, I. N. et al. (2018) 'Improvised Eosin and Leishman as Morphological Stain for Sperm Cell Analysis; Adult Male Wister Rats and Rabbit as a Model of Study', ACTA SCIENTIFIC MICROBIOLOGY. doi: 10.31080/ asmi.2018.01.0004.

Korson, R. (1951) 'A Differential Stain for Nucleic Acids', Stain Technology, pp. 265-270. doi: 10.3109/10520295109113222.

Leishman, W. B. (1901) ‘The Application of Romanowsky’s Stain in Malaria', BMJ, pp. 635-637. doi: 10.1136/ bmj.1.2098.635.

Lisanti, J. A. and Stockert, J. C. (1974) 'Color Differences in Heated and Giemsa Stained Mouse Chromosomes', Stain Technology, pp. 253-256. doi: 10.3109/10520297409116989.

Marwaha, K. (2010) 'Preparation and Examination of Peripheral Blood Smear', Practical Hematology for BDS, pp. 55-55. doi: 10.5005/jp/books/11445_7.

Maslak, P. (2004) 'ALL - Peripheral Smear', ASH Image Bank, pp. 101159-101159. doi: 10.1182/ashimagebank2004-101159.

Mathur, A., Tripathi, A. and Kuse, M. (2013) 'Scalable system for classification of white blood cells from Leishman stained blood stain images', Journal of Pathology Informatics, p. 15. doi: 10.4103/21533539.109883.

Mathur, K. C. (2006) 'The Leucocytes (White Blood Corpuscles: WBC)', Short Textbook of Physiology, pp. 422-422. doi: 10.5005/jp/books/10766_75.

Mehlhorn, H. (2016) 'Giemsa Stain', Encyclopedia of
Parasitology, pp. 1-2. doi: 10.1007/978-3-642-277696_1275-2.

Meyer, J. B. (1945) 'Prefixing with Paradichlorobenzene to Facilitate Chromosome Study', Stain Technology, pp. 121-125. doi: 10.3109/10520294509107146.

Mohan, H. (2013) 'Peripheral Smear Examination in Anaemias', Pathology Practical Book, pp. 223-223. doi: 10.5005/jp/books/11813_55.

Mohan, H. (2017) 'Preparation and Staining of Peripheral Blood Smear', Practical Pathology, pp. 181-181. doi: 10.5005/jp/books/12946_47.

Padma, S. et al. (2018) 'A comparative study of Staining characteristics of Leishman- Geimsa cocktail and Papanicolaou stain in Cervical Cytology', Asian Pacific Journal of Health Sciences, pp. 233-236. doi: 10.21276/apjhs.2018.5.3.32.

Peripheral smear discloses histoplasmosis' (2010) Blood, pp. 3653-3653. doi: 10.1182/blood-2009-09-240002.

Raju, C. R. (1982) 'A Staining Method for Light Microscopic Study of Nucleolar Structure in Plant Cells', Stain Technology, pp. 55-56. doi: 10.3109/10520298209066525.

Ramalingam, K. et al. (2018) 'Comparing the efficacy of leishman-giemsa cocktail stain, giemsa stain, and papanicolaou stain in potentially malignant oral lesions: A study on 540 cytological samples', Journal of Cytology, p. 105. doi: 10.4103/joc.joc_249_16.

Renu, S. and Pati, H. P. (2008) 'Hematopathology Atlas (Peripheral Smear And Bone Marrow Interpretation)'. doi: $10.5005 /$ jp/books/11156.

Sareen, R., Kapil, M. and Gupta, G. N. (2018) 'Incubation and its effect on Leishman stain', Journal of Laboratory Physicians, pp. 357-361. doi: 10.4103/jlp.jlp_154_17.

Sivakumaran, M. (2001) 'The role of WBC adhesion molecules in WBC removal during filtration', Transfusion, pp. 717-717. doi: 10.1046/j.15372995.2001.41050717.x.

Strange, C. A. and Marnell, J. H. (1985) 'An assessment of the Ortho ELT-800 WBC and three-part WBC screen', Clinical \& Laboratory Haematology, pp. 151-156. doi: 10.1111/j.1365-2257.1985.tb00019.x.

Tyler, K. R. (1980) 'Giemsa Poststaining of Sections Stained for Acetyl-Cholinesterase Improves Sensitivity and Contrast', Stain Technology, pp. 49-50. doi: 10.3109/10520298009067898.

Villanueva, A. R. (1974) 'Stain Technology a Bone Stain for Osteoid Seams in Fresh, Unembedded, Mineralized Bone', Stain Technology, pp. 1-8. doi: 10.3109/10520297409116928. 